\title{
Relationship among Urinary Albumin Excretion Rate, Lipoprotein Lipase PvuII Polymorphism and Plasma Fibrinogen in Type 2 Diabetic Patients
}

\author{
M. JAVORSKÝ, M. KOZÁROVÁ, J. ŠALAGOVIČํํㄹ. I. TKÁČ \\ Department of Medicine IV, L. Pasteur University Hospital, and ${ }^{1}$ Institute of Medical Biology, \\ Medical Faculty of P. J. Šafárik University, Košice, Slovakia
}

Received September 22, 2004

Accepted February 4, 2005

On-line available April 26, 2005

\begin{abstract}
Summary
Plasma fibrinogen level represents a strong cardiovascular risk factor and is regulated by an interplay of genetic and environmental factors. Hyperfibrinogenemia frequently occurs in cluster with dyslipidemia within the frame of insulin resistance syndrome (IRS) and type 2 diabetes mellitus. Genetic variants with a pleiotropic effect have been proposed to cause IRS features including hyperfibrinogenemia. We studied the influence of polymorphisms in lipoprotein lipase $(L P L)$ gene, $\beta$-fibrinogen gene $(F I B B)$ and environmental factors on plasma fibrinogen levels in type 2 diabetes patients. 131 type 2 diabetes patients (mean age $62 \pm 10$ years, $33 \%$ male) were genotyped for polymorphisms in $L P L$ gene (intron 6 PvuII, intron 8 HindIII) and FIBB gene $(-148 C / T,-455 G / A)$ by PCR-RFLP method. Fibrinogen was measured by thrombin coagulation method, albuminuria by immunoturbidimetric assay. Polymorphism LPL PvuII showed a genedose effect on fibrinogen levels, with the highest fibrinogen in $P$ - $P$ - homozygotes $(\mathrm{p}=0.05$, analysis of variance). $P$-carriers $(P-P$ - and $P+P$ - combined) had significantly higher fibrinogen levels compared with $P+P+$ homozygotes $(3.74 \pm 1.40 \mathrm{~g} / \mathrm{l}$ vs $3.06 \pm 1.20 \mathrm{~g} / \mathrm{l}, \mathrm{p}=0.03)$. Other studied polymorphisms were not significantly related to fibrinogen levels. Age- and sex-adjusted fibrinogenemia correlated significantly with albuminuria $(r=0.48, p=0.001)$, serum uric acid $(\mathrm{r}=0.42, \mathrm{p}=0.006)$ and serum creatinine $(\mathrm{r}=0.32, \mathrm{p}=0.04)$. Multiple stepwise linear regression identified interaction term of LPL PvuII and albuminuria as an independent predictor of fibrinogen level, explaining $18 \%$ of fibrinogen variance. Albuminuria thus appears to be the best predictor of fibrinogen plasma levels in type 2 diabetic patients. Relationship between albuminuria and fibrinogenemia may be modified by the genotype LPL PvuII, which also shows a weak association with plasma fibrinogen level in type 2 diabetes patients.
\end{abstract}

Key words

Type 2 diabetes mellitus $\bullet$ Fibrinogen $\bullet$ Albuminuria $\bullet$ Lipoprotein lipase gene polymorphisms $\bullet$ Gene-environment interaction

\section{Introduction}

Elevated plasma fibrinogen level is a strong and widely acknowledged cardiovascular risk factor in both diabetic and non-diabetic populations (Maresca et al. 1999, Howard et al. 2000). Playing a crucial role in many 
atherothrombosis-associated processes (hemostasisfibrinolysis, inflammation, platelet aggregation, blood viscosity, smooth muscle proliferation and migration), it has also been proposed to account for a part of the excessive cardiovascular risk in type 2 diabetic patients that remains unexplained after considering the traditional risk factors (Maresca et al. 1999). Notwithstanding its recognized value as a marker for the presence of vascular disease, it remains controversial whether fibrinogen is in a causal relationship or merely in association with the atherosclerotic process (van der Bom et al. 1998).

Fibrinogen production in the liver is regulated by cytokines, mainly by interleukin-6 (IL-6), and is greatly enhanced by the acute phase response to inflammatory processes (Vasse et al. 1996). Hence, fibrinogen elevation might simply reflect the low-grade inflammation associated with vascular disease. On the other hand, increased fibrinogen levels (due to inflammation or other mechanisms) may still participate in the pathogenesis of vascular lesions, i.e. be a true modifier of the atherosclerotic disease and contribute to its progression. Moreover, fibrinogen and fibrin degradation products might in turn enhance the inflammatory aspect of vascular lesions by regulating cytokine production and leukocyte-endothelial interactions (Flick et al. 2004).

The clinically most important and prevalent conditions associated with both elevated fibrinogen level and cardiovascular disease are type 2 diabetes mellitus and the closely related insulin resistance syndrome (IRS) which affect $10-25 \%$ of the general population in developed countries (Imperatore et al. 1998, Boulogne and Vantyghem 2004). However, the mechanisms leading to hyperfibrinogenemia in insulin-resistant and type 2 diabetic subjects have not been elucidated so far, even though a potential role of low-grade inflammation, hyperinsulinemia and albuminuria has been discussed (Zanetti et al. 2001, Barazzoni et al. 2003, Yudkin et al. 2004). Furthermore, the phenomenon of clustering of features within IRS and the high heritability of its components, have led some researchers to propose the existence of "insulin resistance genes" with a pleiotropic effect on metabolism. These genes are supposed to induce changes in multiple metabolic traits with the subsequent development of IRS features including hyperfibrinogenemia (de Lange et al. 2003).

Lipoprotein lipase has emerged as a physiological candidate for the putative insulin resistance gene. Indeed, a considerable body of evidence has accumulated from epidemiological, experimental and transgenic animal studies supporting the role of lipoprotein lipase and its gene in the pathogenesis of insulin resistance. This evidence is primarily derived from the central physiological role of LPL in the lipoprotein and fatty acid metabolism. Furthermore, a transgenic animal model showed, for instance, that overexpression of LPL improves insulin resistance in rabbits on a high-fat diet (Kitajima et al. 2004). A genome-wide linkage analysis and several genetic association studies found a relationship between the region harboring LPL gene on chromosome 8 (8p22) or its polymorphisms, respectively, and insulin resistance syndrome components (dyslipidemia, obesity, hypertension, microalbuminuria) or surrogate indices of insulin sensitivity/resistance (Cai et al. 2004, Goodarzi et al. 2004). Recently, a compelling evidence of both linkage and association of haplotypes of LPL gene with a direct index of insulin sensitivity has been provided (Goodarzi et al. 2004).

Importantly, despite the high heritability of fibrinogen plasma levels (30-50\%) estimated in twin and family studies, common polymorphisms of its gene explain only a negligible part of the fibrinogen level variance (Freeman et al. 2002). This discordance implies existence of additional regulatory genes as well as a potential role for interaction among genetic and environmental factors in determining fibrinogen level.

Hence, the aim of this study was to evaluate the influence of selected genetic polymorphisms of $\beta$-fibrinogen gene and lipoprotein lipase gene (putative insulin resistance gene), as well as environmental factors on the plasma level of fibrinogen in type 2 diabetic patients. Furthermore, we aimed to investigate the presence of potential interactions between genetic factors and diabetic environment such as glycemic control and albuminuria in determining fibrinogen levels.

\section{Methods}

Present study included 131 consecutive type 2 diabetes mellitus patients hospitalized at the Department of Medicine IV of University Hospital in Košice, Slovakia between 2000-2002. Patients with a history of type 2 diabetes mellitus, as defined by the American Diabetes Association, and the absence of any disease known to affect fibrinogen levels such as acute or chronic inflammatory disease, malignancy, hepatic disease, endstage renal disease, acute myocardial infarction or stroke 
within three months before the inclusion into the study, were eligible for this study. The studied patients were not on any lipid lowering treatment affecting fibrinogen levels such as fibrates. The study protocol was approved by the Hospital Ethics Committee. Mean age of the study participants was $62 \pm 10$ years, $33 \%$ were males.

\section{Biochemical measurements}

Blood was withdrawn after an overnight fast. Fibrinogen was determined using thrombin coagulation method (Pacific Hemostasis, USA). Blood glucose, serum creatinine, uric acid, lipids and albumin were measured using routine biochemical assays and glycated hemoglobin was measured using immunoturbidimetric assay (Roche Diagnostica, France). Urinary albumin excretion (UAE) from 24-h urine collection was determined using radial immunodiffusion assay. The categories of normo-, micro- and macroalbuminuria refer to UAE less than $20 \mathrm{mg} / 1,20-199 \mathrm{mg} / \mathrm{l}$ and UAE above $200 \mathrm{mg} / 1$, respectively.

\section{Genotype determination}

DNA was isolated from leukocytes of frozen EDTA-treated whole blood by a high salting-out method and amplified by polymerase chain reaction (PCR) in a Perkins Elmer/Cetus Thermal Cycler. To amplify a 1.3-kb fragment containing the Hind $I I I$ restriction site in intron 8 and a 858-bp fragment containing the PvuII restriction site in intron 6 of the $L P L$ gene, we used a modification of the method described by Ahn et al. (1993). The modifications for the HindIII site were $0.9 \mu \mathrm{mol} / 1$ each primer and 35 cycles. The modifications for the $P v u I I$ site were $0.5 \mu \mathrm{mol} / 1$ each primer, annealing at $67^{\circ} \mathrm{C}$ and 33 cycles. For determination of $\beta$-fibrinogen gene (FIBB) polymorphisms $-148 C / T$ and $-455 G / A$ (restriction sites of HaeIII and HindIII, respectively) we used a modification of method described by Rupert et al. (1999) with forward primer 5' AAG AAT TTG GGA ATG CAA TCT CTG CTA CCT 3' and reverse primer 5' CTC CTC ATT GTC GTT GAC ACC TTG GGA 3'. Blind samples (reagents minus DNA) were included in each PCR reaction to exclude contamination. Amplified products were digested overnight at $37^{\circ} \mathrm{C}$ with appropriate restriction enzyme according to the manufacturer's recommendations (Boehringer Mannheim). After separation on $2 \%$ agarose gels, the resulting fragments were stained with ethidium bromide and visualized with an UV transilluminator. The alleles with the restriction site and the non-cleavable alleles were designated $P+$ and
$P$ - for the $L P L P v u I I, H+$ and $H$ - for $L P L H i n d I I I, G$ and $A$ for the FIBB $-455 G / A$ (HaeIII) and $C$ and $T$ for the $F I B B-148 C / T$ (HindIII) polymorphism, respectively. From the whole sample 120, 120, 124, 117 participants have been successfully genotyped for $F I B B-148 C / T$ and -455G/A, LPL HindIII and PvuII polymorphisms, respectively.

\section{Statistical analysis}

Continuous variables are presented as means \pm $\mathrm{SD}$, except for urinary albumin excretion (UAE) where median, 25th and 75th percentile are shown. Natural logarithmic transformation of variables with skewed distribution was used in the analysis (UAE, triglycerides, fibrinogen). Means or medians of untransformed data are presented in tables for better comprehension. Analysis of variance (ANOVA) with Bonferroni's correction for multiple testing was used for comparison of the means across the genotypes. Student's t-test was applied to compare means between two groups. Hardy-Weinberg equilibrium as well as distribution of the categorical variables across genotypes was examined by a $\chi^{2}$-test. Pearson correlation coefficients adjusted for sex and age were calculated to assess relationships between continuous variables. Multiple stepwise linear regression models were used in the multivariate analysis to reveal the independent predictors of fibrinogen level. Potential interactions between independent variables were examined by introducing interaction terms into the multivariate models. The values of $p<0.05$ were considered statistically significant. Statistical programs Sigmastat v. 2.0 and SPSS v. 10 were used for the analyses.

\section{Results}

The study group consisted of 131 patients with type 2 diabetes mellitus (age $62 \pm 10$ years, BMI $30 \pm 5$ $\mathrm{kg} / \mathrm{m}^{2}$ ) with predominance of women (67 \%), mostly postmenopausal (85\% of women). The clinical and biochemical characteristics of patients according to $L P L$ PvuII genotype are presented in Table 1.

The distributions of the studied genotypes were the following: $\boldsymbol{F I B B}-\mathbf{4 5 5 G} / \boldsymbol{A}: G G 58.3 \%, G A 36.7, \%$ AA $5.0 \%$; FIBB -148C/T: CC $56.7 \%$, CT $38.3 \%$, TT $5.0 \%$; LPL PvuII: $P+P+20.6 \%, P+P-53.8 \%, P-P-$ $25.6 \%$; LPL HindIII: $H+H+35.5 \%, H+H-56.5 \%, H-$ $H-8.0 \%$. Distribution of genotypes did not deviate significantly from the Hardy-Weinberg equilibrium 
(HWE) in any of the polymorphisms.

Across the genotype groups of LPL PvuII polymorphism, the mean fibrinogen plasma level did rise concomitantly with the number of $P$ - alleles in the genotype, indicating thus the presence of a gene-dose effect. As a result, LPL PvuII P-P-homozygotes had the highest mean fibrinogen level, with borderline statistical significance in the analysis of variance (Table 1). Further, carriers of $P$ - allele of $L P L P v u I I$ polymorphism $(P+P$ and $P-P$-) were combined and their mean fibrinogen level was compared with the homozygotes $P+P+$ in the analysis of pooled genotypes. Plasma fibrinogen was significantly higher in the pooled group of $P$ - carriers in comparison with the $P+P+$ group $(3.74 \pm 1.40 \mathrm{~g} / 1$ vs $3.06 \pm$ $1.20 \mathrm{~g} / \mathrm{l}, \mathrm{p}=0.03$; Student's t-test). The mean fibrinogen level did not differ significantly across genotype groups in none of the other studied polymorphisms, neither in the ANOVA test nor in the analysis of pooled genotypes (data not shown). As for the LPL PvuII polymorphism, there was no significant difference in age, sex, diabetes duration, glycated hemoglobin (HbAlc), smoking habits, body mass index, serum creatinine or albuminuria among the genotype groups (Table 1).

Table 1. Clinical and biochemical characteristics of Type 2 diabetes patients according to LPL PVuII genotype

\begin{tabular}{|c|c|c|c|c|c|c|c|c|c|c|}
\hline \multicolumn{11}{|c|}{ LPL PvuII genotype } \\
\hline & \multicolumn{3}{|c|}{$\mathbf{P}+\mathbf{P}+$} & \multicolumn{3}{|c|}{$\mathbf{P}+\mathbf{P}-$} & \multicolumn{3}{|c|}{$\mathbf{P}-\mathbf{P}-$} & \multirow[t]{2}{*}{$\mathbf{p}$} \\
\hline Number of patients & & 24 & & & 63 & & & 30 & & \\
\hline Age (years) & 61 & \pm & 10 & 61 & \pm & 10 & 62 & \pm & 9 & ns \\
\hline$B M I\left(\mathrm{~kg} / \mathrm{m}^{2}\right)$ & 30.7 & \pm & 5.2 & 29.8 & \pm & 5.4 & 30.4 & & 4.3 & ns \\
\hline Sex (\% males $)$ & & 46 & & & 25 & & & 33 & & ns \\
\hline Current smokers (\%) & & 17 & & & 22 & & & 28 & & ns \\
\hline Menopause (\% women) & & 92 & & & 80 & & & 90 & & ns \\
\hline Hypertension (\%) & & 92 & & & 84 & & & 93 & & ns \\
\hline HbAlc (\%) & 7.2 & \pm & 2.0 & 7.7 & \pm & 2.3 & 8.1 & \pm & 2.2 & ns \\
\hline DM duration (years) & 8.0 & \pm & 7.8 & 8.0 & \pm & 6.1 & 10.5 & \pm & 7.5 & ns \\
\hline Insulin treatment (\%) & & 27 & & & 41 & & & 50 & & ns \\
\hline Fibrinogen $(g / l)$ & 3.06 & \pm & 1.20 & 3.64 & \pm & 1.44 & 3.93 & \pm & $1.32 *$ & 0.05 \\
\hline Creatinine $(\mu \mathrm{mol} / \mathrm{l})$ & 108 & \pm & 55 & 94 & \pm & 29 & 100 & & 39 & ns \\
\hline$U A E(m g / l)$ & 10 & 10 ; & & & $; 36$ & 91 & 365 & ; 26 & $; 810$ & ns \\
\hline Uric acid ( $\mu$ mol/l) & 333 & \pm & 114 & 351 & \pm & 117 & 331 & & 102 & ns \\
\hline Total cholesterol & 5.01 & \pm & 1.41 & 5.50 & \pm & 1.23 & 5.46 & \pm & 1.18 & $\mathrm{~ns}$ \\
\hline Triglycerides & 2.65 & \pm & 1.43 & 2.70 & \pm & 1.52 & 2.69 & \pm & 1.45 & ns \\
\hline$L D L-C$ & 2.88 & \pm & 1.08 & 3.39 & \pm & 1.05 & 3.51 & \pm & 1.18 & $\mathrm{~ns}$ \\
\hline$H D L-C$ & 1.00 & \pm & 0.34 & 0.99 & \pm & 0.31 & 0.82 & \pm & 0.25 & ns \\
\hline Apolipoprotein B & 1.02 & \pm & 0.29 & 1.11 & \pm & 0.26 & 1.09 & \pm & 0.27 & $\mathrm{~ns}$ \\
\hline
\end{tabular}

* $P$ - $P$ - vs $P+P+, \mathrm{p}<0.05$, Data shown as mean $\pm \mathrm{SD}$, except for UAE - median; $25 \% ; 75 \%, B M I$ - body mass index, $D M-$ diabetes mellitus, $H b A 1 C$ - glycated hemoglobin, $H D L-C$ - high density lipoprotein cholesterol, $L D L-C-$ low density lipoprotein cholesterol, $S-$ serum, UAE - urinary albumin excretion, WHR - waist-to-hip ratio, $n s-$ not significant

Linear correlation coefficients between fibrinogen and other variables are shown in Table 2. After an adjustment for sex and age, fibrinogen showed a significant positive correlation with urinary excretion rate, uric acid, and serum creatinine level. Across the categories of UAE (normo-, micro-, macroalbuminuria) there was a significant increase of plasma fibrinogen $(\mathrm{g} / \mathrm{l}$; $3.09 \pm 0.97,3.47 \pm 1.18,4.37 \pm 1.86$, ANOVA $\mathrm{p}=0.008$ ) and decrease of albuminemia $(\mathrm{g} / \mathrm{l} ; 43.1 \pm 6.5,40.7 \pm 5.3$, $36.8 \pm 3.6$, ANOVA $p=0.001)$, respectively. 
Table 2. Age and sex adjusted partial correlation coefficients between fibrinogen and other variables $(n=120)$

\begin{tabular}{lcc}
\hline & $\mathbf{r}$ & $\mathbf{p}$ \\
\hline UAE & 0.48 & 0.001 \\
Serum uric acid & 0.42 & 0.006 \\
Serum creatinine & 0.32 & 0.04 \\
BMI & 0.09 & $\mathrm{~ns}$ \\
HbAlc & 0.05 & $\mathrm{~ns}$ \\
Serum albumin & -0.17 & $\mathrm{~ns}$ \\
\hline
\end{tabular}

$B M I$ - body mass index, $H b A 1 C$ - glycated hemoglobin, UAE urinary albumin excretion rate, $n s-$ not significant

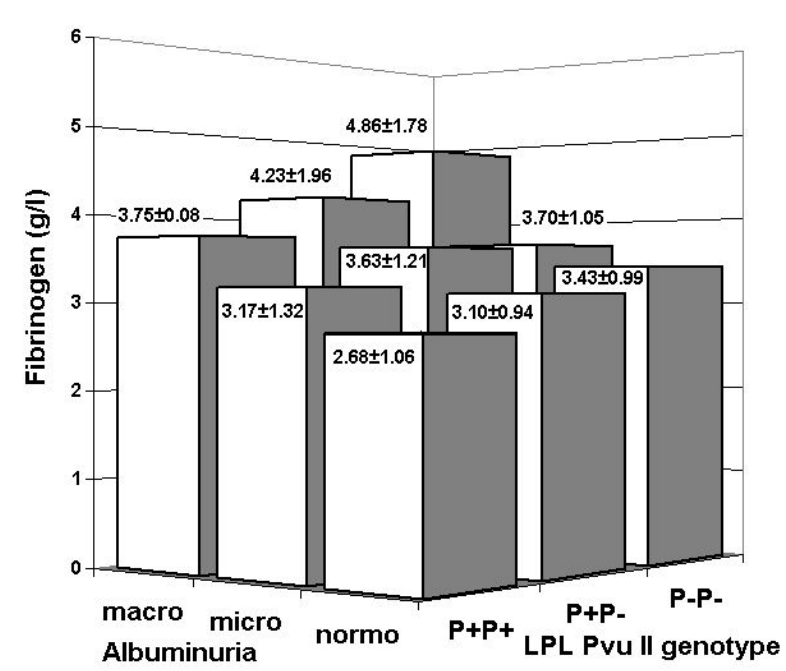

Fig. 1. Relationship among $L P L$ PVuII genotype, category of albuminuria (UAE) and plasma fibrinogen level. Multiple linear regression selected interaction term $L P L P V U I I^{*} \mathrm{UAE}$ as the best predictor of fibrinogen level $(p<0.001)$, explaining $18 \%$ of its variance.

Multiple linear regression analysis was carried out to determine independent predictors of fibrinogen level. With fibrinogen as a dependent variable, included in the multivariate model were all variables that showed association with fibrinogen level in the univariate analysis (UAE, LPL PvuII genotype, creatinine, uric acid) and those that could potentially affect the fibrinogen level according to the physiological knowledge from literature (age, sex, HbA1c, BMI, smoking status).

Urinary albumin excretion (UAE), entered as a categorical variable with values for normo-, micro- and macroalbuminuria, was the only independent predictor of plasma fibrinogen selected in the forward stepwise linear regression model $(\mathrm{P}<0.001, \mathrm{n}=84)$. UAE accounted for
$12 \%$ of fibrinogen variance. When interaction term of $L P L P v u I I *$ UAE was added into the model, it replaced the UAE as the best independent predictor of fibrinogen level ( $\mathrm{P}<0.001)$, augmenting the proportion of explained fibrinogen variance to $18 \%$. Figure 1 depicts the relationship among UAE category, LPL PvuII genotype and plasma fibrinogen.

Other studied polymorphisms showed no significant interaction with albuminuria. Similarly, there was no significant interaction between any of the studied polymorphisms and glycated hemoglobin as a measure of long-term glycemic control (data not shown).

\section{Discussion}

Our findings in the present study show that in patients with type 2 diabetes, plasma fibrinogen level may be best predicted by urinary albumin excretion rate, and that this relationship may be modified by the PvuII polymorphism of the lipoprotein lipase gene, a putative gene for insulin resistance.

Hence, our results suggest a presence of geneenvironment interaction between LPL PvuII genotype and albuminuria in determining fibrinogen levels in diabetic patients. Moreover, our data indicate a possible association between the LPL PvuII genotype and fibrinogen level, given the presence of a gene-dose effect and a significant elevation of fibrinogen in $P$ - carriers compared with $P+P+$ homozygotes.

Association between fibrinogen and albuminuria in type 2 diabetes patients has been previously reported by several authors (Festa et al. 2000, Tkáč et al. 2003). Two recent studies also found a significant association between LPL polymorphisms PvuII or HindIII and microalbuminuria in type 2 diabetic patients (Mattu et al. 2002, Solini et al. 2004). Albuminuria could thus act as a physiological mediator or a statistical confounder of LPL polymorphism-fibrinogenemia relationship. However, in our study we found no significant difference in the magnitude of albuminuria among the LPL PvuII genotype groups.

Although the correlation between fibrinogenemia and albuminuria could be attributed to their common association with the inflammation underlying the insulin resistance syndrome, diabetes, vascular and renal disease, there might also exist another pathophysiological link between these two variables. Notably, in patients with nephrotic range or nearnephrotic range of proteinuria urinary albumin loss with 
subsequent hypoalbuminemia has been shown to stimulate hepatic proteosynthetic rate of plasma proteins including fibrinogen (Zanetti et al. 2001). This pathway has been postulated to act through decreased plasma oncotic pressure as a primary stimulus for the induction of proteosynthesis. On the other hand, it is not clear whether the outlined mechanism also applies to patients with microalbuminuria and non-nephrotic low-grade proteinuria.

Interestingly, our cross-sectional data were consistent with the proposed concept of albuminuriahypoalbuminemia-hyperfibrinogenemia relationship and we could observe a significant decrease of serum albumin levels with a concomitant increase of fibrinogen levels across the categories of normo-, micro- and macroalbuminuria, respectively.

Given the evidence from studies of liver-specific gene expression, it is a conceivable and biologically plausible notion that the regulation of fibrinogen hepatic synthesis in response to environmental stimuli such as hypoalbuminemia and decreased plasma oncotic pressure due to albuminuria is governed by a large network of genes and transcription factors (Schrem et al. 2002). Hence, our observation of genotype-environment interaction between LPL PvuII polymorphism and albuminuria may imply that intronic $L P L$ PvuII polymorphism might be involved in regulation of fibrinogen plasma levels.

In view of the fact that LPL gene, a putative insulin resistance gene, is not expressed in the liver its direct influence on fibrinogen genetic transcription is improbable. Still, its potential association with fibrinogen transcription and plasma level might be mediated either through linkage disequilibrium with other causal gene e.g. with the transcription factor or indirectly, on the biochemical level, through some of the pleiotropic pathophysiologic actions of its product - lipoprotein lipase protein in extrahepatic tissues (Merkel et al. 2002).

There are several limitations of our study that are common to most genetic association studies concerning in particular relatively small sample size, potential confounding variables and population stratification bias (Colhoun et al. 2003). Multiple testing as a source of random associations has been postulated to affect genetic association studies and may also apply to our study. To minimize the impact of multiple comparisons, we used a Bonferroni post hoc test, one of the accepted methods of adjustment in the analysis of variance. To eliminate the effect of potential confounding variables we performed multivariate analysis. Furthermore, small sample size with subsequently small power to detect an effect of minor magnitude may have contributed to our failure to replicate the previously described association of fibrinogen level with $\beta$-fibrinogen gene polymorphisms (Colhoun et al. 2003).

In this study, we have demonstrated that in type 2 diabetic patients, the presence of a gene-environment interaction between albuminuria and LPL PvuII genotype in predicting plasma fibrinogen levels, while this prediction is predominantly mediated by albuminuria. Furthermore, we found a weak association between $L P L$ PvuII polymorphism and plasma fibrinogen. These findings, however, require confirmation and further testing in a more stringent physiological model. A recently proposed novel study approach offered by the systems biology integrating data from multiple fields of biological research (genomics, proteomis, metabolomics, transgenic animals etc.) may yield new original insight into the regulation of fibrinogen (Ghazalpour et al. 2004).

\section{Acknowledgements}

This work was supported by the research grant No. 1/2002/164 from the Medical Faculty of Šafarik University in Košice, Slovak Republik.

\section{References}

AHN YI, KAMBOH MI, HAMMAN RF, COLE SA, FERRELL RE: Two DNA polymorphisms in the lipoprotein lipase gene and their associations with factors related to cardiovascular disease. J Lipid Res 34: 421-428, 1993.

BARAZZONI R, KIWANUKA E, ZANETTI M, CRISTINI M, VETTORE M, TESSARI P: Insulin acutely increases fibrinogen production in individuals with type 2 diabetes but not in individuals without diabetes. Diabetes $\mathbf{5 2}$ : 1851-1856, 2003.

BOULOGNE A, VANTYGHEM MC: Epidemiological data and screening criteria of the metabolic syndrome. (in French) Presse Med 33: 662-665, 2004. 
CAI G, COLE SA, FREELAND-GRAVES JH, MACCLUER JW, BLANGERO J, COMUZZIE AG: Genome-wide scans reveal quantitative trait loci on $8 p$ and $13 q$ related to insulin action and glucose metabolism: the San Antonio Family Heart Study. Diabetes 53: 1369-1374, 2004.

COLHOUN HM, MCKEIGUE PM, SMITH GD: Problems of reporting genetic associations with complex outcomes. Lancet 361: 865-872, 2003.

DE LANGE M, SNIEDER H, ARIENS RA, ANDREW T, GRANT PJ, SPECTOR TD: The relation between insulin resistance and hemostasis: pleiotropic genes and common environment. Twin Res 6: 152-161, 2003.

FESTA A, D'AGOSTINO R, HOWARD G, MYKKANEN L, TRACY RP, HAFFNER SM: Inflammation and microalbuminuria in nondiabetic and type 2 diabetic subjects: the insulin resistance atherosclerosis study. Kidney Int 58: 1703-1710, 2000.

FLICK MJ, DU X, WITTE DP, JIROUŠKOVÁ M, SOLOVIEV DA, BUSUTTIL SJ, PLOW EF, DEGEN JL: Leukocyte engagement of fibrin(ogen) via the integrin receptor $\alpha_{M} \beta_{2} /$ Mac-1 is critical for host inflammatory response in vivo. $J$ Clin Invest 113: 1596-1606, 2004.

FREEMAN MS, MANSFIELD MW, BARRETT JH, GRANT PJ: Genetic contribution to circulating levels of haemostatic factors in healthy families with effects of known genetic polymorphisms on heritability. Arterioscler Thromb Vasc Biol 20: 1354-1361, 2002.

GHAZALPOUR A, DOSS S, YANG X, ATEN J, TOOMEY EM, VAN NAS A, WANG S, DRAKE TA, LUSIS AJ: Toward a biological network for atherosclerosis. J Lipid Res 45: 1793-1805, 2004.

GOODARZI MO, GUO X, TAYLOR KD, QUIÑONES MJ, SAAD MF, YANG H, HSUEH WA, ROTTER JI: Lipoprotein lipase is a gene for insulin resistance in Mexican Americans. Diabetes 53: 214-220, 2004.

HOWARD BV, ROBBINS DC, SIEVERS ML, LEE ET, RHOADES D, DEVEREUX RB, COWAN LD, GRAY RS, WELTY TK, GO OT, HOWARD WJ: LDL cholesterol as a strong predictor of coronary heart disease in diabetic individuals with insulin resistance and low LDL: The Strong Heart Study. Arterioscler Thromb Vasc Biol 20: 830-835, 2000.

IMPERATORE G, RICCARDI G, IOVINE C, RIVELLESE AA, VACCARO O: Plasma fibrinogen: a new factor of the metabolic syndrome. A population-based study. Diabetes Care 21: 649-654, 1998.

KITAJIMA S, MORIMOTO M, LIU E, KOIKE T, HIGAKI Y, TAURA Y, MAMBA K, ITAMOTO K, WATANABE T, TSUTSUMI K, YAMADA N, FAN J: Overexpression of lipoprotein lipase improves insulin resistance induced by a high-fat diet in transgenic rabbits. Diabetologia 47: 1202-1209, 2004.

MARESCA G, DI BLASIO A, MARCHIOLI R, DI MINNO G: Measuring plasma fibrinogen to predict stroke and myocardial infarction: an update. Arterioscler Thromb Vasc Biol 19: 1368-1377, 1999.

MATTU RK, TREVELYAN J, NEEDHAM EWA, KHAN M, ADISESHIAH MA, RICHTER D, MURRAY RG, BETTERIDGE DJ: Lipoprotein lipase gene variants relate to presence and degree of microalbuminuria in Type II diabetes. Diabetologia 45: 905-915, 2002.

MERKEL M, ECKEL RH, GOLDBERG IJ: Lipoprotein lipase: genetics, lipid uptake, and regulation. J Lipid Res 43 : 1997-2006, 2002.

RUPERT JL, DEVINE DV, MONSALVE MV, HOCHACHKA PW: $\beta$-fibrinogen allele frequencies in Peruvian Quechua, a high-altitude native population. Am J Phys Anthropol 109: 181-186, 1999.

SCHREM H, KLEMPNAUER J, BORLAK J: Liver-enriched transcription factors in liver function and development. The hepatocyte nuclear factor network and liver-specific gene expression. Pharmacol Rev 54: 129-158, 2002.

SOLINI A, PASSARO A, FIORETTO P, NANNIPIERI M, FERRANNINI E: Lipoprotein lipase gene variants and progression of nephropathy in hypercholesterolaemic patients with type 2 diabetes. J Intern Med 256: 30-36, 2004.

TKÁČ I, ŠALAGOVIČ J, KOZÁROVÁ M, JAVORSKÝ M, TKÁČOVÁ R, KALINA I: Angiotensin-converting enzyme genotype, albuminuria and plasma fibrinogen in type 2 diabetes mellitus. Wien Klin Wochenschr 115 : $835-839,2003$.

VAN DER BOM JG, DE MAAT MPM, BOTS ML, HAVERKATE F, DE JONG PTVM, HOFMAN A, KLUFT A, GROBBEE DE: Elevated plasma fibrinogen: cause or consequence of cardiovascular disease? Arterioscler Thromb Vasc Biol 18: 621-625, 1998. 
VASSE M, PAYSANT J, SORIA J, COLLET JP, VANNIER JP, SORIA C: Regulation of fibrinogen biosynthesis by cytokines, consequences on the vascular risk. Haemostasis 26 (Suppl 4): 1368-1371, 1996.

YUDKIN JS, JUHAN-VAGUE I, HAWE E, HUMPHRIES SE, DI MINNO G, MARGAGLIONE M, TREMOLI E, KOOISTRA T, MORANGE PE, LUNDMAN P, MOHAMED-ALI V, HAMSTEN A: Low-grade inflammation may play a role in the etiology of the metabolic syndrome in patients with coronary heart disease: the HIFMECH study. Metabolism 53: 852-857, 2004.

ZANETTI M, BARAZZONI R, GARIBOTTO G, DAVANZO G, GABELLI C, KIWANUKA E, PICCOLI A, TOSOLINI M, TESSARI P: Plasma protein synthesis in patients with low-grade nephrotic proteinuria. $A m J$ Physiol 280: E591-E597, 2001.

\section{Reprint requests}

Ivan Tkáč, Department of Medicine IV, Pasteur University Hospital, Rastislavova 43, SK-041 90 Košice, Slovakia. E-mail: ivantkac@central.medic.upjs.sk 